\title{
BMJ Open Utilisation of medications among elderly patients in intensive care units: a cross-sectional study using a nationwide claims database
}

Sun-Young Jung, ${ }^{1}$ Hyun Joo Lee ${ }^{2}$

To cite: Jung S-Y, Lee HJ. Utilisation of medications among elderly patients in intensive care units: a cross-sectional study using a nationwide claims database. BMJ Open 2019;9:e026605. doi:10.1136/ bmjopen-2018-026605

- Prepublication history for this paper and additional material is published online only. To view please visit the journal available online (http://dx.doi.org/10. 1136/bmjopen-2018-026605).

Received 11 September 2018 Revised 2 May 2019 Accepted 14 June 2019

Check for updates

(c) Author(s) (or their employer(s)) 2019. Re-use permitted under CC BY-NC. No commercial re-use. See rights and permissions. Published by BMJ.

${ }^{1}$ College of Pharmacy, ChungAng University, Seoul, Republic of Korea

${ }^{2}$ Department of Thoracic and Cardiovascular Surgery, Seoul National University Hospital, Seoul National University College of Medicine, Seoul, Republic of Korea

Correspondence to

Dr Hyun Joo Lee;

hjleedr@gmail.com

\section{ABSTRACT}

Objectives Clinical practice guidelines for the management of pain and sedation in critically ill patients have been developed and applied; however, there is limited data on medication use among elderly patients. This study identifies current practice patterns for analgosedative use in mechanically ventilated elderly patients in Korea using a national claims database.

Design Cross-sectional study.

Setting and participants Ventilated elderly patients aged 65 years or older in intensive care units (ICUs) from an aged patients' national claims database in Korea

Primary outcome measures Use of sedatives including benzodiazepines, opioids and non-opioid analgesics, neuromuscular blocking agents (NMBAs) and antipsychotic drugs were analysed by the duration of mechanical ventilation (MV), age and time.

Results From 2012 to 2016, 22677 elderly patients underwent MV in 267 general or tertiary ICUs. Mean age was $77.2( \pm 6.9)$ years and the median duration of MV was 4.1 days; $77.2 \%$ of patients received sedatives, $65.0 \%$ analgesics, $29.1 \%$ NMBAs and $19.6 \%$ antipsychotics. Midazolam (62.0\%) was the most commonly prescribed medication. The proportions of sedatives, analgesics and NMBAs increased, whereas the percentages of persondays decreased with longer MV duration $(p<0.01)$. With advanced age, the prevalence and duration of sedative, analgesic and NMBA use decreased (adjusted OR $(95 \% \mathrm{Cl})$ 0.98 (0.97 to 0.98) in all three classes) while antipsychotic did not (adjusted OR 1.00 (1.00-1.01)). Annually, benzodiazepines showed reduced administration $(76.2 \%$ in 2012 and $71.4 \%$ in $2016, p<0.01$ ), while daily opioid dose increased (21.6 in 2012 vs $30.0 \mathrm{mg}$ in 2016, $\mathrm{p}<0.01$ ). Conclusions The prevalence of sedative, analgesic and NMBAs use and daily opioid doses were lower, whereas antipsychotic use was higher compared with those in previous studies in adult patients. The findings warrant further studies investigating appropriateness and safety of medication use that consider clinical severity scores with a focus on elderly patients in ICUs.

\section{INTRODUCTION}

Sedation and pain management are necessary to both reduce discomfort and treat underlying diseases, in mechanically ventilated intensive care unit (ICU) patients. Clinical
Strengths and limitations of this study

- This population-based study demonstrates a real-world practice patterns in sedative, analgesic, neuromuscular blocking agent and antipsychotic use among elderly patients in the intensive care unit using a nationwide Korean database.

- The administration of these medications was analysed by the duration of mechanical ventilation, patient age and annual trends.

- Since this study analysed a claims database, it was not able to assess clinical severity scores.

- The determination of causal relationship is limited since it was a cross-sectional study.

practice guidelines for the management of pain, agitation, sedation and delirium in adult patients have been developed and have improved general understanding of the importance of sedation and pain medication in critically ill patients. ${ }^{12}$ Elderly patients are prone to adverse drug reactions due to altered pharmacokinetics and pharmacodynamics as well as underlying diseases. Patients over 65 years of age comprise up to $50 \%$ of all ICU admissions ${ }^{3}$ and patients over 80 years of age comprise $18 \%$ of critical care cases. ${ }^{4}$ Although benzodiazepines, opioids and antipsychotics are commonly used for sedation and treatment of pain and delirium in critical care, these medications are strongly recommended to avoid in geriatric populations due to the risk of adverse drug events including delirium and cognitive impairment, based on the Beers or Screening Tool of Older Persons' Potentially Inappropriate Prescriptions criteria. ${ }^{56}$ These criteria have been applied in community-dwelling older adults and have recently been applied to hospitalised elderly patients. ${ }^{78}$ However, it is difficult to apply these criteria to critically ill patients with diverse urgent situations. Recent clinical guidelines have reinforced immobility and 


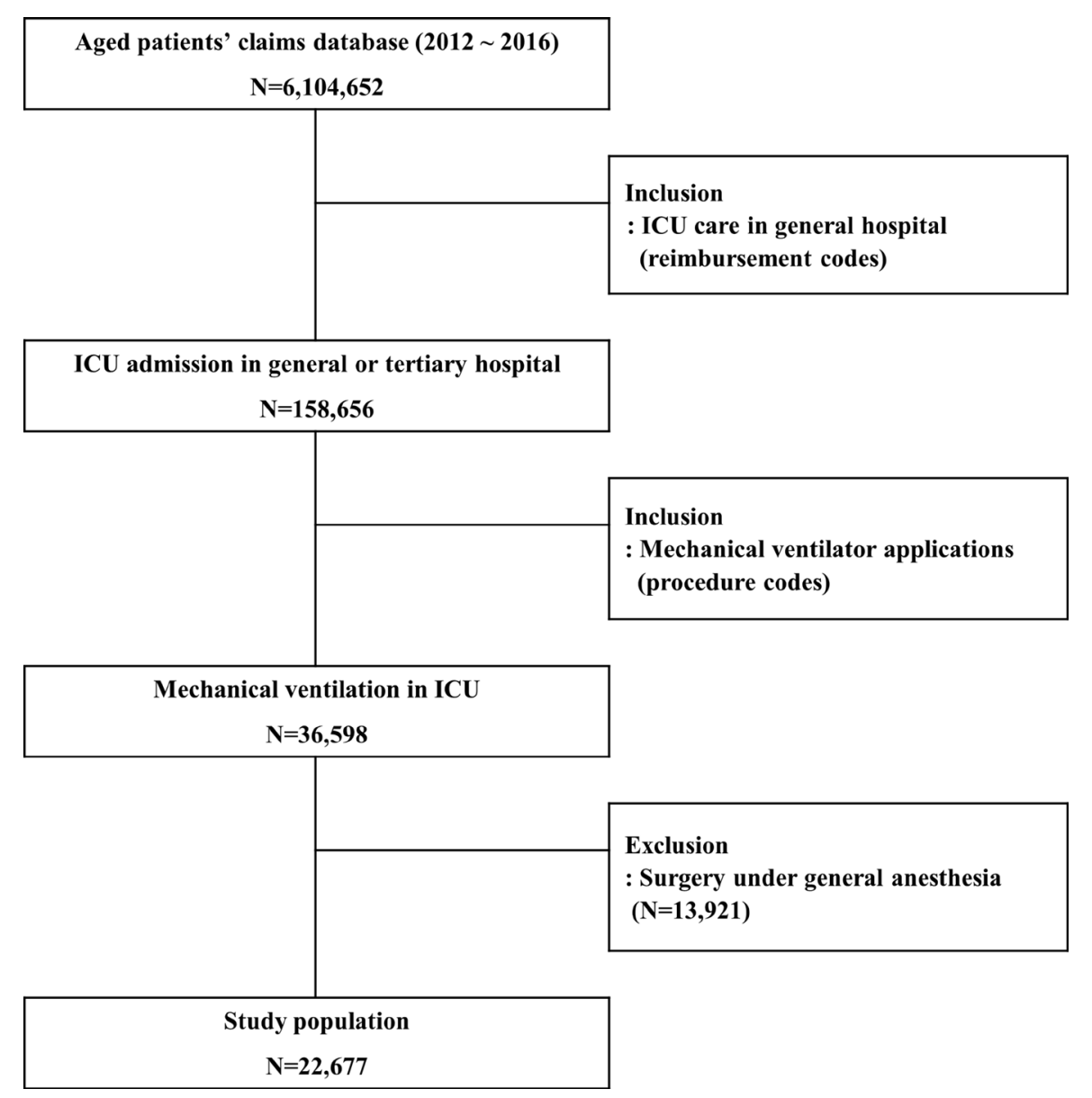

Figure 1 Flow diagram of patient selection. We selected elderly patients who underwent mechanical ventilation in the ICU based on reimbursement and procedure codes. Patients who underwent surgeries under general anaesthesia were excluded. $\mathrm{ICU}$, intensive care unit.

sleep issues but there were few considerations regarding proper choice, practical doses and administrative routes of sedative, analgesics and adjunctive therapies in elderly patients. Available data on the estimated real-life use of medications for pain and sedation considering their potential complications in elderly ICU patients have been lacking. ${ }^{2}$ We conducted a population-based cross-sectional study using a nationwide Korean database to provide realworld data regarding the current practices of critical care medication use among mechanically ventilated elderly patients, with a focus on the use of sedatives, analgesics, neuromuscular blocking agents (NMBAs) and antipsychotic medications compared with current guidelines for adult patients. We analysed the patterns of medication use according to the duration of mechanical ventilation (MV), patient age and annual trends and assessed patient factors related to the use of sedatives and analgesics in elderly patients.

\section{METHODS}

\section{Data source and study population}

We performed a cross-sectional study using the national claims database for the period from 2012 to 2016. Most of the population in Korea is covered by national insurance.
The aged patients' sample (APS) data used in this study was a $20 \%$ stratified sample directly proportional to the age and sex of Korean elderly patients (aged 65 years or older) served from the Health Insurance Review and Assessment Service (HIRA-APS-2016-0064). The database includes information regarding diagnoses made in accordance with the International Classification of Diseases 10th revision (ICD-10), institutional information, patient characteristics, medication prescriptions, medical procedures and healthcare expenditures. Critically ill patients who underwent MV in the ICU were eligible for this study (figure 1). We only included patients admitted to the ICU in the general or tertiary hospital, as determined using reimbursement codes. We excluded patients who underwent surgical procedures under general anaesthesia in operating rooms due to differences in the usage of analgesics for surgical pain. In cases of patients with multiple ICU admissions, only the first admission was included in our analyses.

\section{Study medications}

We assessed the use of sedatives, analgesics including opioids, NMBAs and antipsychotics. In total, 124 medications were assessed (32 sedatives, 10 opioid analgesics, 44 non-opioid analgesics, 12 NMBAs and 26 antipsychotics). 
The detailed medications included in the analyses are described in (online supplementary table 1). The sedatives included benzodiazepines (eg, midazolam and lorazepam), propofol, ketamine, etomidate and barbiturates. The analgesics included opioids and non-opioid analgesics administered as adjunctive therapy. Fentanyl, morphine, remifentanil, sufentanil and pethidine were the representative opioid analgesics. The daily dose of opioids was calculated based on oral morphine-equivalent doses (MEDs).${ }^{910}$ We also classified opioids by route of administration (intravenous, enteral, or topical). We defined non-opioid analgesics as acetaminophen (AAP), non-steroidal anti-inflammatory drugs (NSAIDs) and anticonvulsants (eg, gabapentin and carbamazepine) used to treat neuropathic pain. ${ }^{12}$ As NMBAs, we included rocuronium, vecuronium and cisatracurium. Antipsychotic medications included both conventional (eg, haloperidol) and atypical (eg, risperidone and quetiapine) antipsychotics.

\section{Patient characteristics}

We identified demographic characteristics (age, sex), route of admission, primary disease and comorbidities. We used ICD-10 codes to identify primary diseases and comorbidities. The primary diseases included cardiac disease, cerebrovascular disease, chronic pulmonary disease, gastrointestinal disease, liver disease, malignancy, pneumonia, poisoning, renal disease, sepsis and trauma. The chronic comorbid conditions included Charlson Comorbidity Index ${ }^{11}$ hypertension and transplantation (online supplementary table 2). In addition, we assessed continuous renal replacement therapy (CRRT), duration of MV, length of ICU stays, length of hospitalisation and in-hospital mortality. In-hospital mortality was identified as the total mortality reported outcomes at the time of hospital discharge.

\section{Statistical analysis}

We performed subgroup analyses by the duration of MV, patient age and annual trends. We categorised the study population into three groups based on MV duration ( $<48$ hours, 48 hours to $<7$ days, or 7 days or more). The characteristics of the study population and patterns of medication use were assessed based on MV subgroups. Three age groups were used (65 $\leq$ age $<75$ years, $75 \leq$ age $<80$ years, or 80 years or more), according to the distribution of our population. The annual trends from 2012 to 2016 regarding medication use in critically ill elderly patients with MV were analysed.

Continuous variables were presented as means and SD for age and as median values with an IQR for other variables. Categorical variables were presented as frequencies and proportion. In addition, the duration of use of each medication was presented as percentage person-days, which was calculated by dividing the days of medication use by the duration of ICU stay. Comparisons between groups were analysed by Pearson and Mantel-Haenszel $\mathrm{X}^{2}$ or Fisher's exact tests for categorical variables and analysis of variance or Kruskal-Wallis tests for continuous variables. To assess factors associated with sedatives or opioids use, we estimated adjusted odds ratios and their 95\% CIs using multivariable logistic regression models. $\mathrm{P}$ values $<0.05$ were considered statistically significant. However, when comparing medication use according to MV duration, age group and annual trends, we applied a Bonferroni correction to correct for multiple comparisons: therefore, we considered $\mathrm{p}$ values $<0.0167$ as statistically significant. Analyses were performed using SAS V.9.4.

\section{Patients and public involvement}

This study was a cross-sectional analysis of a national sample claims database. The database is anonymised and served without identifiers of the study participants. The patients were not involved in designing or conducting this study. We intend to disseminate the results by paper publication in a journal.

\section{RESULTS}

\section{Patient demographics}

APS data from 2012 to 2016 shows that 158656 patients $(2.6 \%)$ were admitted to general or tertiary hospital ICUs. Among 36598 patients with MV, we excluded those who underwent surgical procedures under general anaesthesia; subsequently, we analysed 22677 patients in 267 ICUs of general $(n=224)$ and tertiary $(n=43)$ hospitals (figure 1). Their mean age was $77.2( \pm 6.9)$ years and the proportion of male patients was greater than that of females. More than half of the patients were admitted through the emergency department. The median duration of MV was 4.1 days (IQR 2-10) and the in-hospital mortality rate was $57.0 \%$. We categorised the study population into three groups by MV duration ( $<48$ hours, 48 hours to $<7$ days and 7 days or more). The baseline characteristics of each group are described in table 1 . There were no differences in the distributions of patients in age or time categories among the three groups of MV duration ( $\mathrm{p}=0.08$ and $\mathrm{p}=0.31$, respectively). The proportions of men to women increased with longer MV duration. Pneumonia (19.3\%) was the most common primary disease associated with admission to the ICU. The group with less than 48 hours of MV had a higher rate of cardiac disease $(p<0.01)$, cerebrovascular disease $(p=0.04)$ and liver disease $(p<0.01)$; however, the group with longer MV duration ( $M V \geq 7$ days) showed more chronic pulmonary disease, malignancy and pneumonia $(\mathrm{p}<0.01)$. The group with longer MV also showed a higher rate of application of CRRT $(p<0.01)$. The median ICU and hospital stays increased with greater MV duration $(\mathrm{p}<0.01)$.

\section{Analysis of medications based on MV duration}

Administration of medications classified as sedatives, analgesics, NMBAs and antipsychotics, based on MV duration are shown in table 2. Among 22677 patients, $77.2 \%$ were administered sedative drugs and $50.6 \%$ used opioids during 
Table 1 Characteristics of critically ill elderly patients with mechanical ventilation

\begin{tabular}{|c|c|c|c|c|c|}
\hline \multirow[b]{2}{*}{ Variables } & \multirow{2}{*}{$\begin{array}{l}\begin{array}{l}\text { Total } \\
(n=22677)\end{array} \\
n(\%)\end{array}$} & \multirow{2}{*}{$\begin{array}{l}\text { MV<48 hours } \\
(n=5480) \\
n(\%)\end{array}$} & \multirow{2}{*}{$\begin{array}{l}48 \mathrm{hrs} \leq \mathrm{MV}<7 \text { days } \\
(\mathrm{n}=8903)\end{array}$} & \multirow{2}{*}{$\begin{array}{l}M V \geq 7 \text { days } \\
(n=8294) \\
n(\%)\end{array}$} & \multirow[b]{2}{*}{ P value* } \\
\hline & & & & & \\
\hline $65-69$ & $3345(14.8)$ & $822(15.0)$ & $1306(14.7)$ & $1217(14.7)$ & 0.08 \\
\hline $70-74$ & $5206(23.0)$ & $1217(22.2)$ & $2111(23.7)$ & $1878(22.6)$ & \\
\hline $85-89$ & $2598(11.5)$ & $685(12.5)$ & 1002 (11.3) & $911(11.0)$ & \\
\hline 90- & $978(4.3)$ & $261(4.8)$ & $390(4.4)$ & 327 (3.9) & \\
\hline \multicolumn{6}{|l|}{ Year } \\
\hline 2012 & $4642(20.5)$ & $1131(20.6)$ & $1782(20.0)$ & $1729(20.8)$ & 0.31 \\
\hline 2016 & 4456 (19.6) & $1086(19.8)$ & 1755 (19.7) & 1615 (19.5) & \\
\hline Sex (Male) & $12932(57.0)$ & $2938(53.6)$ & $5018(56.4)$ & $4976(60.0)$ & $<0.01$ \\
\hline Admission route (emergency) & $14777(65.2)$ & $3631(66.3)$ & $5910(66.4)$ & $5236(63.1)$ & $<0.01$ \\
\hline Charlson's comorbidity score & $2(1-4)$ & $2(1-4)$ & $2(1-4$ & $2(1-4)$ & $<0.01$ \\
\hline \multicolumn{6}{|l|}{ Primary diseases } \\
\hline Cardiac disease & $2902(12.8)$ & $935(17.1)$ & $1215(13.7)$ & $752(12.8)$ & $<0.01$ \\
\hline Cerebrovascular disease & $2670(11.8)$ & $674(12.3)$ & 1066 (12.0) & $930(11.2)$ & 0.04 \\
\hline Chronic pulmonary disease & $1241(5.5)$ & $170(3.1)$ & $547(6.1)$ & $524(6.3)$ & $<0.01$ \\
\hline Sepsis & $1901(8.4)$ & $465(8.5)$ & $672(7.5)$ & $764(9.2)$ & 0.05 \\
\hline Trauma & $1082(4.8)$ & $303(5.5)$ & 399 (4.5) & $380(4.6)$ & 0.02 \\
\hline CRRT use & $3579(15.8)$ & $750(13.7)$ & 1449 (16.3) & $1380(16.6)$ & $<0.01$ \\
\hline MV duration (days) & $4.1(2-10)$ & $1.0(0.3-1.1)$ & $3.3(2.3-5.0)$ & $13.1(9.1-21)$ & $<0.01$ \\
\hline ICU length of stay (days) & $7(3-15)$ & $2(1-4)$ & $5(3-8)$ & $17(11-28)$ & $<0.01$ \\
\hline Hospital stay (days) & $19(8-49)$ & $6(2-18.5)$ & $15(6-36)$ & $36(20-82)$ & $<0.01$ \\
\hline In-hospital mortality & $12936(57.0)$ & $3747(68.4)$ & $4474(50.3)$ & $4715(56.8)$ & $<0.01$ \\
\hline
\end{tabular}

Data presented as $\mathrm{n}(\%)$ or median (IQR). Only age presented as mean (SD).

${ }^{*} \mathrm{P}$-value by $\mathrm{X}^{2}$ or Fisher's exact test for categorical variables, by analysis of variance for age and by Kruskal-Wallis test for other continuous variables.

CRRT, continuous renal replacement therapy; ICU, intensive care unit; MV, mechanical ventilation.

their ICU stays. The proportions of patients administered medications significantly increased in proportion to MV duration in all drug classes $(\mathrm{p}<0.01$, respectively). However, the percentages of person-days showed decreasing trends with greater MV duration, with the exception of antipsychotics. Midazolam was the most commonly used sedative drug $(62.0 \%)$. The proportion of opioid use increased with MV duration (41.1\% in MV $<48$ hours, $47.5 \%$ in
48 hours $\leq \mathrm{MV}<7$ days and $60.2 \%$ in $\mathrm{MV} \geq 7$ days, $\mathrm{p}<0.001$ ). Among routes of administration, intravenous infusion including bolus increased with longer MV duration while enteral or topical applications decreased with daily MED dose $(p<0.01$, respectively). Non-opioid analgesics were used in $34.0 \%$ of patients. Among 11477 patients who used opioids, $38.7 \%$ were administered non-opioid analgesics simultaneously. The proportion of patients concomitantly 
Table 2 Use of critical care medications classified by the duration of mechanical ventilation

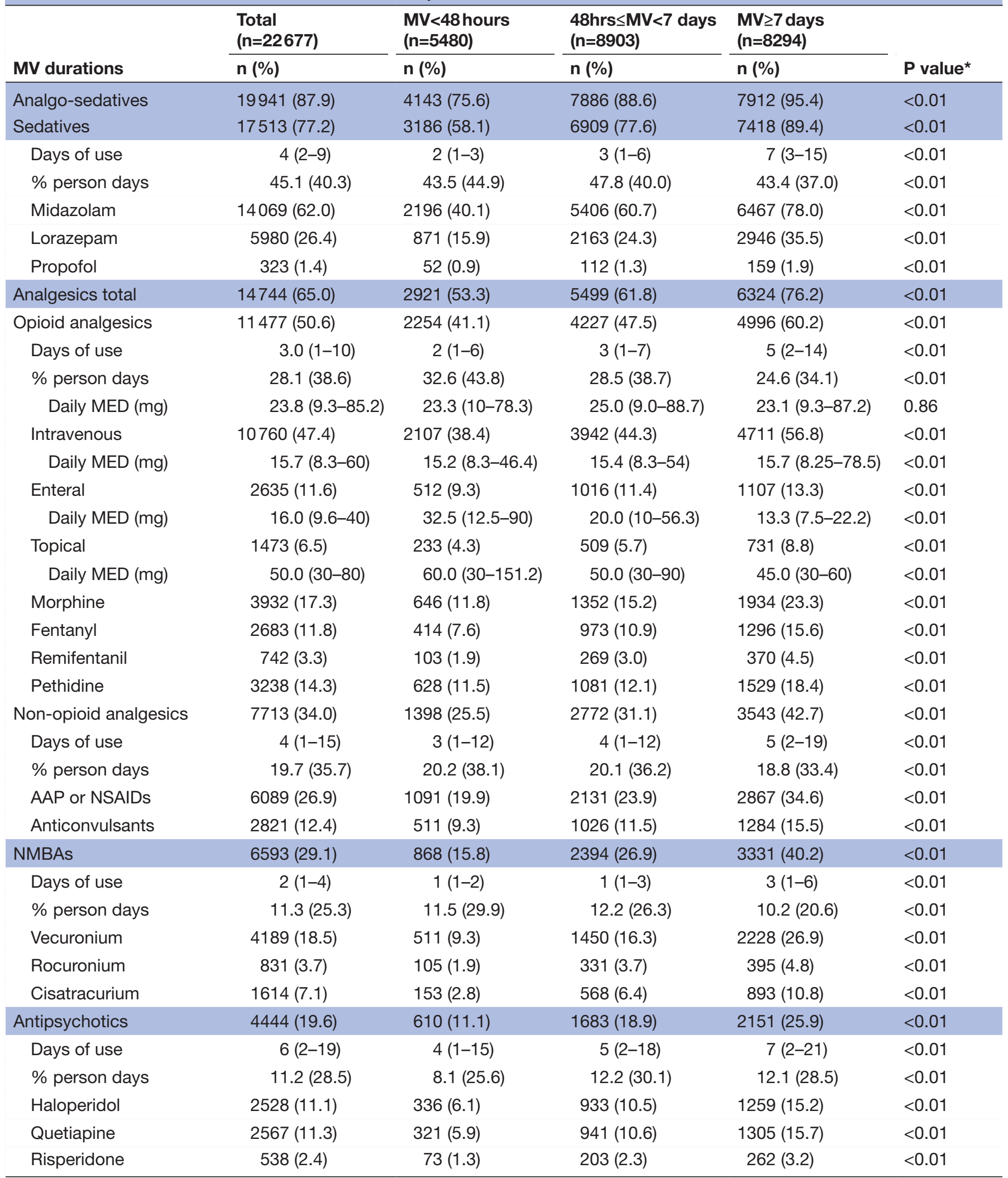

Data presented as $\mathrm{n}(\%)$ or as median (IQR). Only \% person-days presented as mean (SD).

${ }^{*} \mathrm{P}$-value by $\mathrm{X}^{2}$ or Fisher's exact tests for categorical variables, and by Kruskal-Wallis test for continuous variables.

AAP, acetaminophen; MED, morphine-equivalent dose; MV, mechanical ventilation; NMBA, neuromuscular blocking agent; NSAID, nonsteroidal anti-inflammatory drug. 
$48 \mathrm{hr} \leq \mathrm{MV}<7$ days

$(\mathrm{N}=5,499)$

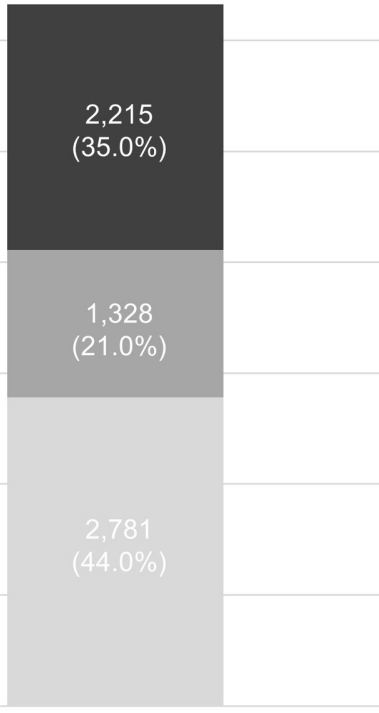

$M V \geq 7$ days

$(\mathrm{N}=6,324)$

\section{Opioid Non-opioid Opioid+non-opioid}

Figure 2 Concomitant use of opioid and non-opioid analgesics in analgesic groups based on the duration of MV. The proportions of patients administered opioid and non-opioid simultaneously increased with MV duration whereas those of opioidonly and non-opioid-only decreased $(\mathrm{p}<0.01)$. Data are indicated as numbers of patients with proportions in brackets. MV, mechanical ventilation.

administered opioid combined with non-opioid analgesics was significantly increased by $25.0 \%, 27.3 \%$ and $35.0 \%$ in the $M V<48$ hours, 48 hours $\leq \mathrm{MV}<7$ days, and $M V \geq 7$ days, respectively (figure 2). NMBA was administered to 6593 patients $(29.1 \%)$ for a median of 2 days (IQR 1-4). Antipsychotic medications were used in 4444 patients (19.6\%). Within the MV $\geq 7$ days group, one of four patients used antipsychotic medications, with increased percentages of person-days $(\mathrm{p}<0.01)$.

Table 3 shows the association between patient demographics or clinical variables, and sedative or opioid use. Male sex, longer MV duration, CRRT application, longer ICU stay and admission via the emergency department were related to higher prescriptions of sedatives, whereas older age was related to a lower use of sedatives. For opioids, longer MV duration, CRRT application and longer ICU stay were related to higher use. Male sex was related to lower opioid prescriptions.

Table 4 shows the patterns of the combined use of sedatives, analgesics, NMBAs and antipsychotics classified by duration of MV. Among 22677 patients, 89.1\% were prescribed at least one medication during MV application. The proportion of patients administered medications in combination significantly increased with MV duration ( $45.3 \%$ in $\mathrm{MV}<48$ hours, $64.5 \%$ in 48 hours $\leq \mathrm{MV}<7$ days and $81.3 \%$ in $\mathrm{MV} \geq 7$ days, $\mathrm{p}<0.01)$.

\section{Analysis of medication use based on age}

The current practices of medication administration in elderly patients based on age groups $(65 \leq$ age $<75$ years,
$75 \leq$ age $<80$ years and 80 years or more) are shown in table 5. The prescriptions of sedatives, analgesics and NMBAs decreased with increasing age $(80.1 \%, 78.3 \%$ and $73.6 \%$ for sedatives in patients $65 \leq$ age $<75$ years, $75 \leq$ age $<80$ years and 80 years or more; $68.7 \%, 65.9 \%$ and $60.6 \%$ for analgesics; and $33.5 \%, 30.3 \%$ and $23.6 \%$ for NMBAs, $\mathrm{p}<0.01$ respectively). The proportions of patients who did not require any medications were $9.0 \%$ in those $65 \leq$ age $<75$ years, $10.7 \%$ in those $75 \leq$ age $<80$ years and $13.0 \%$ in those over 80 years of age $(\mathrm{p}<0.01)$.

However, antipsychotic use showed no significant change based on age groups, at $20.1 \%$ in those $65 \leq$ age $<75$ years, $19.4 \%$ in those $75 \leq$ age $<80$ years and $19.2 \%$ in those aged 80 years or more $(\mathrm{p}=0.11)$. When adjusting for sex, MV duration, disease status and duration of ICU stay, the adjusted ORs (95\% CI) for sedative, analgesic, NMBA and antipsychotics use were 0.98 (0.97 to 0.98$), 0.98$ (0.97 to 0.98$), 0.98$ (0.97 to 0.98$)$ and 1.00 (1.00 to 1.01 ), respectively).

Annual differences in medication use are presented in table 6. Sedative drugs, especially benzodiazepines (mainly midazolam and lorazepam), showed reduced annual administration $(76.2 \%$ in $2012,75.6 \%$ in 2013 , $73.6 \%$ in $2014,72.6 \%$ in 2015 and $71.4 \%$ in $2016, p<0.01$ ). There were no changes in the ratios of patients who used opioids annually, while the median daily doses of opioids increased from 2012 to 2016 (21.6, 22.4, 21.3, 26.0 and $30.0 \mathrm{mg}, \mathrm{p}<0.01)$. Among opioids, fentanyl and remifentanil use increased, while morphine and pethidine use decreased during the same period. Among non-opioid 
Table 3 Demographic and clinical variables associated with uses of sedatives and opioids

\begin{tabular}{|c|c|c|}
\hline & $\begin{array}{l}\text { Sedatives use } \\
(n=17513)\end{array}$ & $\begin{array}{l}\text { Opioids use } \\
(n=11477)\end{array}$ \\
\hline & $\begin{array}{l}\text { Multivariable OR } \\
(95 \% \mathrm{CI})\end{array}$ & $\begin{array}{l}\text { Multivariable OR } \\
(95 \% \mathrm{Cl})\end{array}$ \\
\hline $\begin{array}{l}\text { Age, years (vs } \\
65-74)\end{array}$ & 1 & 1 \\
\hline $75-79$ & 0.91 (0.83 to 0.99$)$ & 0.94 (0.88 to 1.01$)$ \\
\hline 80 or more & 0.72 (0.66 to 0.78$)$ & 0.81 (0.76 to 0.86$)$ \\
\hline Male sex & 1.36 (1.27 to 1.46$)$ & 0.92 (0.87 to 0.98$)$ \\
\hline $\begin{array}{l}\text { MV duration (vs } \\
M V<48 \text { hours) }\end{array}$ & 1 & 1 \\
\hline $\begin{array}{l}48 \mathrm{hrs} \leq \mathrm{MV}<7 \\
\text { days }\end{array}$ & 2.20 (2.03 to 2.37 ) & 1.24 (1.16 to 1.33$)$ \\
\hline $\mathrm{MV} \geq 7$ days & 3.43 (3.07 to 3.84$)$ & 1.64 (1.51 to 1.79$)$ \\
\hline CRRT apply & 1.16 (1.06 to 1.28$)$ & 1.64 (1.52 to 1.77$)$ \\
\hline $\begin{array}{l}\text { Administration } \\
\text { route (Emergency) }\end{array}$ & 1.14 (1.06 to 1.22$)$ & 0.96 (0.91 to 1.02$)$ \\
\hline \multicolumn{3}{|l|}{ Primary disease } \\
\hline Cardiac disease & 0.83 (0.75 to 0.92$)$ & 0.96 (0.88 to 1.04$)$ \\
\hline $\begin{array}{l}\text { Cerebrovascular } \\
\text { disease }\end{array}$ & 0.52 (0.47 to 0.57$)$ & 0.51 (0.46 to 0.56$)$ \\
\hline $\begin{array}{l}\text { Chronic } \\
\text { pulmonary } \\
\text { disease }\end{array}$ & 2.09 (1.72 to 2.53$)$ & 1.14 (1.01 to 1.29$)$ \\
\hline Gastrointestinal & 0.89 (0.67 to 1.19$)$ & 2.10 (1.62 to 2.73$)$ \\
\hline Liver disease & 0.59 (0.44 to 0.80$)$ & $1.11(0.84$ to 1.45$)$ \\
\hline Malignancy & 1.20 (1.05 to 1.36$)$ & 2.44 (2.20 to 2.71$)$ \\
\hline Pneumonia & 1.26 (1.14 to 1.39$)$ & 0.96 (0.89 to 1.03$)$ \\
\hline Poisoning & 1.26 (1.01 to 1.57$)$ & 0.58 (0.49 to 0.70$)$ \\
\hline Renal disease & 0.67 (0.56 to 0.80$)$ & 0.97 (0.83 to 1.12$)$ \\
\hline Sepsis & 0.86 (0.76 to 0.97$)$ & $0.92(0.84$ to 1.02$)$ \\
\hline Trauma & 0.68 (0.59 to 0.79$)$ & 1.46 (1.29 to 1.66$)$ \\
\hline $\begin{array}{l}\text { Length of ICU stay } \\
\text { (continuous) }\end{array}$ & 1.03 (1.03 to 1.04$)$ & $1.02(1.01$ to 1.02$)$ \\
\hline
\end{tabular}

CRRT, continuous renal replacement therapy; ICU, intensive care unit; MV, mechanical ventilation.

analgesics, AAPs and NSAIDs showed decreased use. The results showed increasing use of NMBAs and antipsychotic agents each year. For NMBAs, vecuronium usage decreased, while cisatracurium and rocuronium use increased.

\section{DISCUSSION}

In this population-based study of critically ill elderly patients, $87.9 \%$ patients were administered more than one analgo-sedative during their ICU stay. Sedatives were administered in $77.2 \%$ of the study population and midazolam was the most commonly used medication $(62.0 \%)$. Longer MV duration increased the usage of sedatives, analgesics and NMBAs; however, the percentage of person-days decreased. However, the prevalence and person-days for antipsychotic prescriptions increased with MV duration and did not decrease with age. The proportion of patients who did not require any medications increased with advanced age $(\mathrm{p}<0.01)$.

Overall, our analysis showed annual trends partially in line with recent recommendations in adult patients, especially within each class of medications as well as decreased use of medications with safety issues and increased use of medications with fewer adverse effects and complications. Although midazolam was the most commonly used medication in this study, the significant annual reduction of benzodiazepines $(76.2 \%, 75.6 \%, 73.6 \%, 72.6 \%$ and $71.4 \%$ from 2012 to 2016, $\mathrm{p}<0.01$ ) and increased use of opioids (increased daily MEDs with even proportions) reflected analgesia-based sedation. ${ }^{2}$ Among opioids, the use of pethidine, which is not recommended for analgesia in the ICU due to its potential for neurologic side effects, ${ }^{5} 12$ significantly decreased, whereas remifentanil use increased over time $(\mathrm{p}<0.01)$. Vecuronium use decreased among NMBAs, while cisatracurium and rocuronium use increased $(p<0.01)$ from 2012 to 2016. Cisatracurium is preferred in critically ill patients due to its pharmacological characteristics including the low risks of renal and hepatic failure. ${ }^{13}$ Within the same period, NMBAs showed increased administration; however, the median duration of total usage was concentrated within 48 hours (2.0 days, IQR 1-4). This may reflect current guideline recommendations to use NMBAs in the early MV period within 48 hours. $^{14}$

In contrast, the present study had several unique findings in elderly patients compared with the general guidelines for adults. First, in this elderly population, the daily MED of opioid was lower and the prevalence of antipsychotics use was higher compared with those in previous studies of adult ICU patients. The daily median MEDs of opioids in the present study were $23.8 \mathrm{mg}$ (IQR 9.3-85.2) (23.3 mg median MED in MV $\leq 48$ hours, $25.0 \mathrm{mg}$ in 48 hours $<\mathrm{MV}<7$ days and $23.1 \mathrm{mg}$ in $\mathrm{MV} \geq 7$ days); in comparison, Burry et $a l^{15}$ reported mean MEDs of $23.2 \mathrm{mg}$ for $\mathrm{MV} \leq 48$ hours, $62.9 \mathrm{mg}$ for 48 hours $<\mathrm{MV}<7$ days and $106.0 \mathrm{mg}$ for $\mathrm{MV} \geq 7$ days. The administration of antipsychotics in the present study (20.1\% in $65 \leq$ age $<75$ years, $19.4 \%$ in $75 \leq$ age $<80$ years and $19.2 \%$ in $\geq 80$ years) was higher than that in the Burry study $(9.6 \%)$. This difference may be due to a difference in age distribution between the studies (mean $77.2 \pm 6.9$ years in this study and $60.8 \pm 16.7$ years in the Burry study) which reflects the cautious use of opioids considering potential safety concerns and potentially higher prevalence of delirium in elderly patients. Compared with antipsychotic prescription, the relatively low prevalence of delirium in the present study could be due to an under-reporting of diagnostic codes in a clinical setting. The prevalence of delirium is easily underestimated without applying organised evaluation tools. ${ }^{2}$ Burry et al also discussed the low assessment of delirium along with the gap between actual clinical practice and expectations. ${ }^{15}$ Propofol also showed 
Table 4 Patterns of the combined use of study drugs classified by the duration of mechanical ventilation

\begin{tabular}{|c|c|c|c|c|}
\hline & $\begin{array}{l}M V<48 \text { hours } \\
(n=5480)\end{array}$ & $\begin{array}{l}48 \mathrm{hrs} \leq \mathrm{MV}<7 \text { days } \\
(\mathrm{n}=8903)\end{array}$ & $\begin{array}{l}M V \geq 7 \text { days } \\
(n=8294)\end{array}$ & \\
\hline MV durations & n (\%) & n (\%) & $\mathrm{n}(\%)$ & P value* \\
\hline Number of drug classes in combination & & & & $<0.01$ \\
\hline 0 & $1257(22.9)$ & $894(10.0)$ & $320(3.9)$ & \\
\hline 1 & $1740(31.8)$ & $2263(25.4)$ & $1229(14.8)$ & \\
\hline 2 & $1687(30.8)$ & $3382(38.0)$ & $3132(37.8)$ & \\
\hline 3 & $713(13.0)$ & $1998(22.4)$ & $2721(32.8)$ & \\
\hline 4 & $83(1.5)$ & $366(4.1)$ & $892(10.8)$ & \\
\hline Sedatives & 3186 & 6909 & 7418 & \\
\hline \multicolumn{5}{|l|}{ Used in combination with: } \\
\hline Analgesics & $1964(61.6)$ & $4522(65.5)$ & $5830(78.6)$ & $<0.01$ \\
\hline NMBAs & $501(15.7)$ & $1532(22.2)$ & $2071(27.9)$ & $<0.01$ \\
\hline Antipsychotics & $723(22.7)$ & 2206 (31.9) & 3225 (42.4) & $<0.01$ \\
\hline Analgesics & 2921 & 5499 & 6324 & \\
\hline \multicolumn{5}{|l|}{ Used in combination with: } \\
\hline Sedatives & $1964(67.2)$ & $4522(82.2)$ & $5830(92.2)$ & $<0.01$ \\
\hline NMBAs & $560(19.2)$ & $1579(28.7)$ & $2673(42.3)$ & $<0.01$ \\
\hline Antipsychotics & 466 (16.0) & $1239(22.5)$ & $1811(28.6)$ & $<0.01$ \\
\hline NMBAs & 868 & 2394 & 3331 & \\
\hline \multicolumn{5}{|l|}{ Used in combination with: } \\
\hline Analgesics & $560(64.5)$ & $1579(66.0)$ & $2673(80.3)$ & $<0.01$ \\
\hline Sedatives & 723 (83.3) & 2206 (92.2) & $3225(96.8)$ & $<0.01$ \\
\hline Antipsychotics & $110(12.7)$ & $494(20.6)$ & $1037(31.1)$ & $<0.01$ \\
\hline Antipsychotics & 610 & 1683 & 2151 & \\
\hline \multicolumn{5}{|l|}{ Used in combination with: } \\
\hline Analgesics & $466(76.4)$ & 1239 (73.6) & $1811(84.2)$ & $<0.01$ \\
\hline Sedatives & $501(82.1)$ & 1532 (91.0) & 2071 (96.3) & $<0.01$ \\
\hline NMBAs & $110(18.0)$ & $494(37.9)$ & $1037(48.4)$ & $<0.01$ \\
\hline
\end{tabular}

${ }^{*} \mathrm{P}$-value by $\mathrm{X}^{2}$ test.

$\mathrm{MV}$, mechanical ventilation; NMBA, neuromuscular blocking agent.

a relatively lower prevalence and decreased use with increasing age in our study. Payer et al reported propofol as the second most commonly used sedative $(20 \%$ in 44 French ICUs). ${ }^{16}$ The relatively lower use of propofol in this study might be due to concerns over adverse effects in Korea, such as propofol infusion syndrome, ${ }^{17}$ as well as old age. Dundee reported a relatively sensitive response in the elderly, with reduced requirement of induction dose and marked hypotension and apnea. ${ }^{18}$

Second, the proportions of patients administered single-drug or multi-drug classes in combination significantly increased with MV duration $(\mathrm{p}<0.01)$ (table 4$)$. Among those administered sedatives, $61.6 \%$ of patients in the $\mathrm{MV}<48$ hours group used analgesics simultaneously, compared with $65.5 \%$ and $78.6 \%$ in the 48 hours $\leq \mathrm{MV}<7$ days and in $\mathrm{MV} \geq 7$ days groups $(\mathrm{p}<0.01)$. Patients administered benzodiazepines showed higher rates of antipsychotic use in combination than that in the non-benzodiazepine group ( $24.0 \%$ vs $7.0 \%, \mathrm{p}<0.01)$. The proportion of patients with delirium was higher in the benzodiazepine group $(0.35 \%)$ than that in the non-benzodiazepine group $(0.08 \%) \quad(\mathrm{p}<0.01)$. The administration of benzodiazepines was related to an increased risk of delirium and increased use of antipsychotics. Stollings $e t$ al reported that the plasma concentration of lorazepam was associated with delirium and that avoidance of benzodiazepines may result in the reduced risk of delirium. ${ }^{19}$

An advantage of the present study is its inclusion of extensive medications within the analysis (online supplementary table 1). The use of non-opioid analgesics, including AAPs, NSAIDs and anticonvulsants used for neuropathic pain, ${ }^{20}$ were analysed in conjunction with opioids. Opioids are initial analgesics for critically ill patients; however, non-opioid analgesics can reduce opioid dose and lower the risks of complications. Among 11477 patients who used opioids, 4446 (38.7\%) were 
Table 5 Use of critical care medications classified by patient age groups

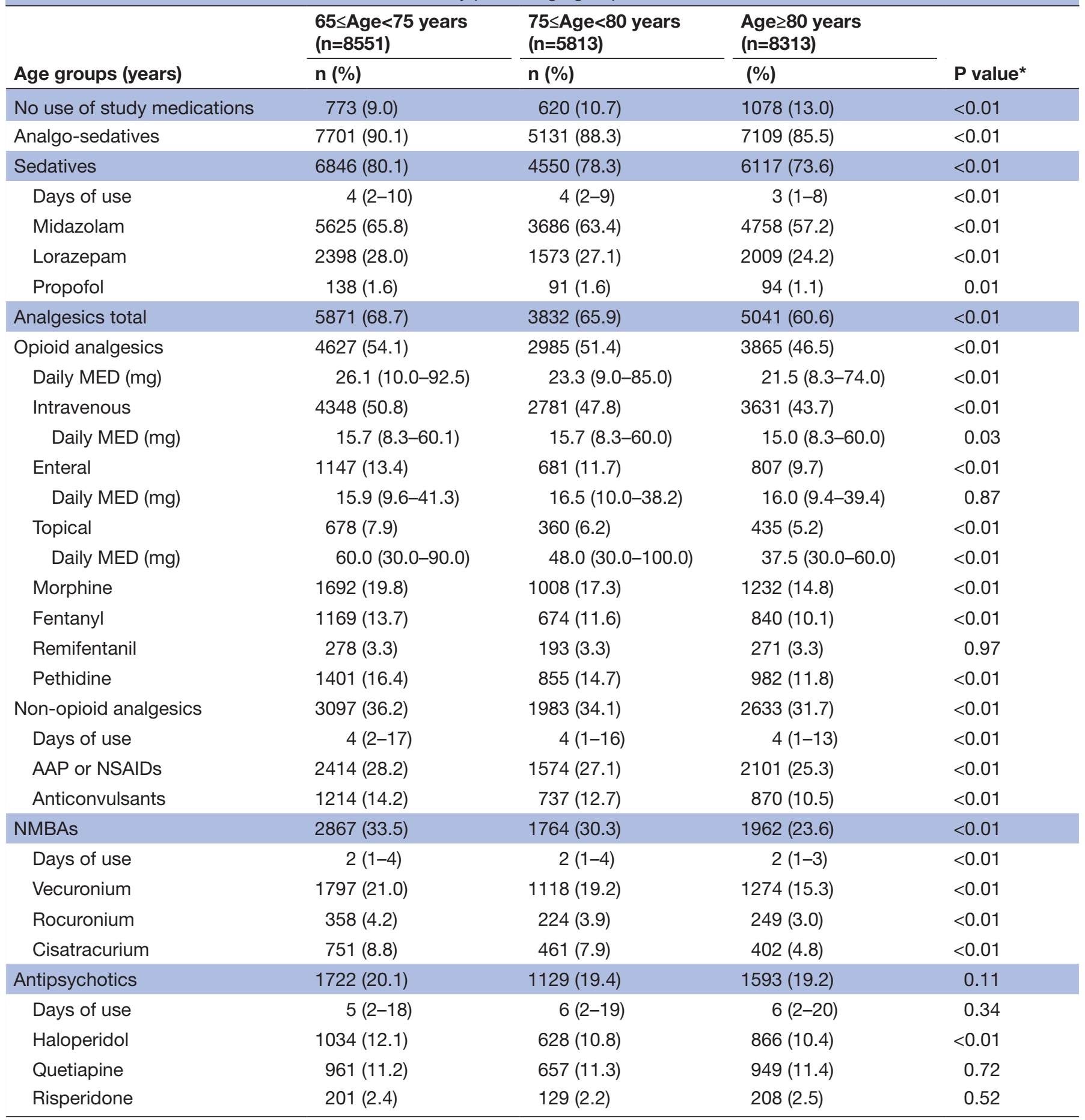

Data presented as $\mathrm{n}(\%)$ or as median (IQR).

Annual trends in the administration of sedative, analgesic, NMBA and antipsychotic medications.

${ }^{*} \mathrm{P}$-value by $\mathrm{X}^{2}$ or Fisher's exact tests for categorical variables, and by Kruskal-Wallis test for other continuous variables.

AAP, acetaminophen; MED, morphine-equivalent dose; MV, mechanical ventilation; NMBA, neuromuscular blocking agent; NSAID, nonsteroidal anti-inflammatory drug.

administered non-opioid analgesics simultaneously. Patients administered both opioid and non-opioid analgesics had significantly lower daily doses of opioids than those administered only opioids (median daily MED $23.3 \mathrm{mg}$ (IQR 10.0-79.8) in combined administration vs
24.4 mg (IQR 9.0-90.0) for opioid only, $\mathrm{p}<0.01$ ), which may reflect a reduction in opioid requirements.

The study has several limitations. We could not assess the degrees of sedation, pain, or delirium in comparison with medications and clinical severity scores because these 
Table 6 Annual trends in the use of critical care medications in elderly, 2012-2016

\begin{tabular}{|c|c|c|c|c|c|c|}
\hline & $\begin{array}{l}2012 \\
(n=4642)\end{array}$ & $\begin{array}{l}2013 \\
(n=4478)\end{array}$ & $\begin{array}{l}2014 \\
(n=4513)\end{array}$ & $\begin{array}{l}2015 \\
(n=4588)\end{array}$ & $\begin{array}{l}2016 \\
(n=4456)\end{array}$ & \\
\hline Year & n (\%) & n (\%) & n (\%) & n (\%) & n (\%) & P value* \\
\hline Sedatives & 3679 (79.3) & $3511(78.4)$ & $3440(76.2)$ & $3516(76.6)$ & $3367(75.6)$ & $<0.01$ \\
\hline Days of use & $4(2-10)$ & $4(2-9)$ & $4(2-9)$ & $3(2-8)$ & $3(2-8)$ & $<0.01$ \\
\hline Midazolam & 2947 (63.5) & $2822(63.0)$ & $2798(62.0)$ & $2801(61.1)$ & 2701 (60.6) & $<0.01$ \\
\hline Propofol & $72(1.6)$ & $58(1.3)$ & $54(1.2)$ & $57(1.2)$ & $82(1.8)$ & 0.37 \\
\hline Analgesics total & 3060 (65.9) & $2956(66.0)$ & $2893(64.1)$ & $2924(63.7)$ & $2911(65.3)$ & 0.12 \\
\hline Opioid analgesics & $2308(49.7)$ & $2276(50.8)$ & 2299 (50.9) & $2292(50.0)$ & $2302(51.7)$ & 0.20 \\
\hline Daily MED (mg) & $21.6(9.6-71.5)$ & $22.4(9.1-69.4)$ & $21.3(8.8-72.5)$ & $26.0(9.6-88.3)$ & $30.0(9.9-147.7)$ & $<0.01$ \\
\hline Daily MED (mg) & $15.0(10.0-36.6)$ & $16.2(9.5-42.5)$ & $15.2(10.0-37.6)$ & $16.9(9.8-41.4)$ & $16.7(8.4-39.6)$ & 0.88 \\
\hline Topical & $272(5.9)$ & $283(6.3)$ & $286(6.3)$ & $328(7.1)$ & $304(6.8)$ & 0.02 \\
\hline Daily MED (mg) & $60.0(30.0-90.0)$ & $54.0(30.0-108.0)$ & $51.3(30.0-80.0)$ & $32.1(30.0-60.0)$ & $47.6(30.0-87.0)$ & $<0.01$ \\
\hline Morphine & $880(19.0)$ & $825(18.4)$ & $813(18.0)$ & $747(16.3)$ & $667(15.0)$ & $<0.01$ \\
\hline Fentanyl & $495(10.7)$ & $528(11.8)$ & $503(11.1)$ & $607(13.2)$ & $550(12.3)$ & $<0.01$ \\
\hline Remifentanil & $70(1.5)$ & 87 (1.9) & $104(2.3)$ & $124(2.7)$ & $357(8.0)$ & $<0.01$ \\
\hline Pethidine & $699(15.1)$ & $674(15.1)$ & $652(14.4)$ & $619(13.5)$ & $594(13.3)$ & $<0.01$ \\
\hline $\begin{array}{l}\text { Non-opioid } \\
\text { analgesics }\end{array}$ & $1658(35.7)$ & 1536 (34.3) & 1455 (32.2) & 1439 (31.4) & $1625(36.5)$ & 0.46 \\
\hline Days of use & $4(1-12)$ & $4(1-14)$ & $4(1-17)$ & $4(1-15)$ & $5(2-18)$ & $<0.01$ \\
\hline Cisatracurium & $152(3.3)$ & $279(6.2)$ & $364(8.1)$ & $446(9.7)$ & $373(8.4)$ & $<0.01$ \\
\hline Antipsychotics & 785 (16.9) & 803 (17.9) & $928(20.6)$ & 967 (21.1) & 961 (21.6) & $<0.01$ \\
\hline Days of use & $5(2-17)$ & $6(2-21)$ & $6(2-18)$ & $6(1-20)$ & $6(2-20)$ & 0.45 \\
\hline Haloperidol & 478 (10.3) & 466 (10.4) & $523(11.6)$ & $557(12.1)$ & 504 (11.3) & 0.01 \\
\hline Quetiapine & 368 (7.9) & $453(10.1)$ & $558(12.4)$ & $568(12.4)$ & 620 (13.9) & $<0.01$ \\
\hline Risperidone & $112(2.4)$ & $104(2.3)$ & $96(2.1)$ & $108(2.4)$ & $118(2.6)$ & 0.49 \\
\hline
\end{tabular}

Data presented as $\mathrm{n}(\%)$ or as median (IQR).

*P-value by $\mathrm{X}^{2}$ or Fisher's exact tests for categorical variables, and by Kruskal-Wallis test for other continuous variables.

AAP, acetaminophen; MED, morphine-equivalent dose; NMBA, neuromuscular blocking agent; NSAID, non-steroidal anti-inflammatory drug.

data were not available in the claims database. In addition, we could not identify a causal relationship between sedative drug use and clinical outcomes. Although current guidelines suggest dexmedetomidine instead of benzodiazepines ${ }^{21}$ and reduced proportion of patients who used benzodiazepines in our population could be moved to dexmedetomidine, we could not determine the use of dexmedetomidine because it is not covered by national insurance in Korea. Despite these limitations, this study demonstrates real-world practice patterns using a nationally representative database of critically ill elderly patients under MV. ${ }^{22}$

\section{CONCLUSIONS}

Annual trends in reduced use of sedatives including benzodiazepines and increased opioid daily dose reflecting the analgesia-based sedation principle were observed in elderly critical care patients. However, a lower prevalence of sedative, analgesic and NMBA use was 
observed for advanced age groups with relatively lower daily opioid dose, lower prescriptions of propofol and higher prevalences of antipsychotic use compared with previous studies on adult ICU patients. Further studies investigating appropriateness and safety of medication use that consider clinical severity scores in elderly critical care patients are required to develop elderly specific patient guidelines on the usage of sedatives, analgesics, NMBAs and antipsychotics.

Contributors Conceived and designed the study: SYJ and HJL. Analysed the data: SYJ. Wrote the paper: SYJ and HJL. Both provided final approval and agree to be accountable for all aspects of the work.

Funding This research was supported by the Basic Science Research Program through the National Research Foundation of Korea (NRF) funded by the Ministry of Education (grant no. NRF-2017R1D1A1B03032231). The funder had no role in the study design, data collection and analysis, decision to publish or preparation of the manuscript.

Competing interests SYJ has nothing to disclose. HJL is supported by the International Fellowship Program funded by the Takeda Science Foundation.

Patient consent for publication Not required.

Ethics approval Institutional review board of Seoul National University Hospital (IRB No. 1806-121-952).

Provenance and peer review Not commissioned; externally peer reviewed.

Data sharing statement Data may be obtained from a third party and are not publicly available.

Open access This is an open access article distributed in accordance with the Creative Commons Attribution Non Commercial (CC BY-NC 4.0) license, which permits others to distribute, remix, adapt, build upon this work non-commercially, and license their derivative works on different terms, provided the original work is properly cited, appropriate credit is given, any changes made indicated, and the use is non-commercial. See: http://creativecommons.org/licenses/by-nc/4.0/.

\section{REFERENCES}

1. Barr J, Fraser GL, Puntillo K, et al. Clinical practice guidelines for the management of pain, agitation, and delirium in adult patients in the intensive care unit. Crit Care Med 2013;41:263-306.

2. Devlin JW, Skrobik Y, Gélinas C, et al. Clinical practice guidelines for the prevention and management of pain, agitation/sedation, delirium, immobility, and sleep disruption in adult patients in the ICU. Crit Care Med 2018;46:e825-e873.

3. Bagshaw SM, Webb SA, Delaney A, et al. Very old patients admitted to intensive care in Australia and New Zealand: a multi-centre cohort analysis. Crit Care 2009;13:R45.

4. Han CH, Kim YS, Park EC, et al. Patterns of Critical Care and Factors Associated with Survivor and Prognosis in Critical Care in Korea Using National Health Insurance Service (NHIS) Database.
Ilsan: NHIS Ilsan Hospital Institute of Health Insurance and Clinical Research, 2017.

5. Fick DM, Semla TP. By the American Geriatrics Society 2015 Beers Criteria Update Expert Panel. American Geriatrics Society 2015 Updated Beers Criteria for Potentially Inappropriate Medication Use in Older Adults. J Am Geriatr Soc 2015;63:2227-46.

6. O'Mahony D, O'Sullivan D, Byrne S, et al. STOPP/START criteria for potentially inappropriate prescribing in older people: version 2. Age Ageing 2015;44:213-8.

7. Hill-Taylor B, Walsh KA, Stewart S, et al. Effectiveness of the STOPP/ START (Screening Tool of Older Persons' potentially inappropriate Prescriptions/Screening Tool to Alert doctors to the Right Treatment) criteria: systematic review and meta-analysis of randomized controlled studies. J Clin Pharm Ther 2016;41:158-69.

8. Petersen AW, Shah AS, Simmons SF, et al. Shed-MEDS: pilot of a patient-centered deprescribing framework reduces medications in hospitalized older adults being transferred to inpatient postacute care. Ther Adv Drug Saf 2018;9:523-33.

9. Dowell D, Haegerich TM, Chou R. CDC guideline for prescribing opioids for chronic pain--United States, 2016. JAMA 2016;315:1624-45.

10. Nielsen S, Degenhardt L, Hoban B, et al. Comparing opioids: a guide to estimating oral morphine equivalents (OME) in research: National Drug and Alcohol Research Centre Sydney, Australia, 2014. NDARC Technical Report No. 329.

11. Quan H, Sundararajan V, Halfon P, et al. Coding algorithms for defining comorbidities in ICD-9-CM and ICD-10 administrative data. Med Care 2005;43:1130-9.

12. Erstad BL, Puntillo K, Gilbert HC, et al. Pain management principles in the critically ill. Chest 2009;135:1075-86.

13. Szakmany T, Woodhouse T. Use of cisatracurium in critical care: a review of the literature. Minerva Anestesiol 2015;81:450-60.

14. Rhodes A, Evans LE, Alhazzani W, et al. Surviving sepsis campaign: international guidelines for management of sepsis and septic shock: 2016. Intensive Care Med 2017;43:304-77.

15. Burry LD, Williamson DR, Perreault MM, et al. Analgesic, sedative, antipsychotic, and neuromuscular blocker use in Canadian intensive care units: a prospective, multicentre, observational study. Can J Anaesth 2014;61:619-30.

16. Payer JF, Chanques G, Mantz J, et al. Current practices in sedation and analgesia for mechanically ventilated critically ill patients. Anesthesiology 2007;106:687-95.

17. Mirrakhimov AE, Voore P, Halytskyy O, et al. Propofol infusion syndrome in adults: a clinical update. Crit Care Res Pract 2015;2015:1-10.

18. Dundee JW, Robinson FP, McCollum JS, et al. Sensitivity to propofol in the elderly. Anaesthesia 1986;41:482-5.

19. Stollings JL, Thompson JL, Ferrell BA, et al. Sedative Plasma Concentrations and Delirium Risk in Critical IIIness. Ann Pharmacother 2018;52:513-21.

20. Attal N, Cruccu G, Baron R, et al. EFNS guidelines on the pharmacological treatment of neuropathic pain: 2010 revision. Eur $J$ Neurol 2010;17:1113-e88.

21. Fraser GL, Devlin JW, Worby CP, et al. Benzodiazepine versus nonbenzodiazepine-based sedation for mechanically ventilated, critically ill adults: a systematic review and meta-analysis of randomized trials. Crit Care Med 2013;41:S30-8.

22. Anthony Celi L, Mark RG, Stone DJ, et al. "Big data" in the intensive care unit. Closing the data loop: American Thoracic Society, 2013. 